\title{
Multiple-Dose Intravenous Tranexamic Acid in Total Knee Arthroplasty in Patients with Rheumatoid Arthritis: A Randomized Controlled Study
}

\section{Bing-xin Kang}

Shanghai Guanghua Hospital of Integrated Traditional Chinese and Western Medicine,Shanghai University of Traditional Chinese Medicine https://orcid.org/0000-0001-8829-3853

Hui Xu

Shanghai Guanghua Hospital of Integrated Traditional Chinese and Western Medicine, Shanghai University of Traditional Chinese Medicine

\section{Chen-xin Gao}

Shanghai Guanghua Hospital of Integrated Traditional Chinese and Western Medicine

\section{Sheng Zhong}

Shanghai Guanghua Hospital of Integrated Traditional Chinese and Western Medicine

\section{Jing Zhang}

Shanghai Guanghua Hospital of Integrated Traditional Chinese and Western Medicine Jun Xie

Shanghai Guanghua Hospital of Integrated Traditional Chinese and Western Medicine

\section{Song-tao Sun}

Shanghai Guanghau Hospital of Integrated Traditional Chinese and Western Medicine Ying-hui Ma

Shanghai Guanghua Hospital of Integrated Traditional Chinese and Western Medicine

\section{Xi-rui Xu}

Shanghai Guanghua Hospital of Integrated Traditional Chinese and Western Medicine

\section{Chi Zhao}

Shanghai Guanghua Hospital of Integrated Traditional Chinese and Western Medicine, Shanghai University of Traditional Chinese Medicine

Wei-tao Zhai

Shanghai Guanghau Hospital of Integrated Traditional Chinese and Western Medicine

Lian-bo Xiao ( $\nabla$ xiao_lianbo@163.com )

https://orcid.org/0000-0001-9305-0776

\section{Research article}

Keywords: Total knee arthroplasty, rheumatoid arthritis, Tranexamic acid, Blood loss 
Posted Date: July 15th, 2020

DOl: https://doi.org/10.21203/rs.3.rs-42566/v1

License: (c) (i) This work is licensed under a Creative Commons Attribution 4.0 International License. Read Full License 


\section{Abstract}

Background: To identify the efficacy and safety of multiple doses of intravenous tranexamic acid (IVTXA) on perioperative blood loss in patients with rheumatoid arthritis (RA) who underwent primary unilateral total knee arthroplasty (TKA).

Methods: In this single-center, single-blind randomized controlled clinical trial, ten male and 87 female participants aged 50-75 years, with RA who underwent unilateral primary TKA were randomly assigned $(1: 1)$ to receive a single dose of IV-TXA $(1 \mathrm{~g})$ for $3 \mathrm{~h}$ (group A) or three doses of IV-TXA $(1 \mathrm{~g})$ for 3,6 , and $12 \mathrm{~h}$ (group B) postoperatively. Primary outcomes were total red blood cell loss (TBL), hidden red blood loss $(\mathrm{HBL})$ and maximum hemoglobin $(\mathrm{Hb})$ drop. Secondary outcomes were transfusion rate and levels of D-dimer. All parameters were measured post-operatively during inpatient hospital stay.

Results: Between September 2019 and May 2020, 104 participants were randomized. 7 were lost followup. Mean TBL, HBL, and maximum $\mathrm{Hb}$ drop in group B $(506.1 \pm 227.0 \mathrm{~mL}, 471.6 \pm 224.0 \mathrm{~mL}$, and $17.5 \pm$ $7.7 \mathrm{~g} / \mathrm{L}$, respectively) were significantly lower than those in groups $\mathrm{A}(608.8 \pm 244.8 \mathrm{~mL}, P=0.035 ; 574.0$ $\pm 242.3 \mathrm{~mL}, P=0.033$; and $23.42 \pm 9.2 \mathrm{~g} / \mathrm{L}, P=0.001$, respectively). No episode of transfusion occurred. D-dimer level was lower in group $B$ than in group $A$ on post-operative day $1(P<0.001)$, and the incidence of thromboembolic events was similar between the two groups $(P>0.05)$.

Conclusion: Three doses of post-operative IV-TXA could further reduced blood loss, maximum Hb drop, and diminished the postoperative fibrinolytic responses without increasing the risk of complications.

Trial registration: The trial was registered in Chinese Clinical Trial Registry (ChiCTR1900025013).

Name of the registry: Clinical observation of multiple dose use of tranexamic acid in patients with rheumatoid arthritis after total knee arthroplasty. Prospective registration, ChiCTR1900025013. Registered 7 August 2019, http://www.chictr.org.cn/showproj.aspx?proj=41375

\section{Background}

Rheumatoid arthritis (RA) is an autoimmune disease with erosive arthritis as the main clinical manifestation. The basic pathological manifestations are synovitis, pannus formation, and articular cartilage and bone destruction gradually occur, which eventually leads to joint deformity and dysfunction[1]. RA main age of onset is 40-60 years old[2]. The application of anti-rheumatic drugs and biological agents has delayed the progress of RA bone destruction, a rate of RA patients receive total knee arthroplasty (TKA) has gradually decreased over the past decades. However, in patients with severe knee joint destruction in the advanced stage, TKA is a kind of an effective way to improve knee function and quality of life[3,4]. The mean blood loss during TKA perioperative period can reach $1470 \mathrm{~mL}[5], \mathrm{RA}$ patients have a higher incidence of anemia[6], low levels of hemoglobin $(\mathrm{Hb})$ before surgery increases the risk of blood transfusion after surgery[7]. Blood transfusion increases the risk of postoperative infections and prolongs hospital stay[8]. It is vital important to reduce TKA perioperative blood loss and accelerate 
postoperative recovery. Perioperative use of multi-mode blood management successfully reduced perioperative blood loss $[9,10]$. Based on the combined blood management of multiple strategies, after 2010 , the total blood transfusion rate of TKA was less than $4 \%[11]$.

Fibrinolysis caused by surgical trauma is one of the main causes of postoperative bleeding. Although the application of tourniquet reduces intraoperative bleeding, with the release of postoperative tourniquet, fibrinolysis will be enhanced and postoperative bleeding will increase[12]. The anti-fibrinolytic drug tranexamic acid (TXA), by preventing the combination of plasminogen and fibrin, protects fibrin from degradation by plasmin to achieve hemostasis[13].

Clinical studies have confirmed that in patients with Osteoarthritis (OA), TXA can reduce the incidence of anemia after TKA and reduce the rate of blood transfusion, while not increasing the incidence of thromboembolism[14-[15][16]17]. However, there is still no consensus on the optimal dosage and timing of TXA administration[18]. Patients with RA may be accompanied by mild to moderate anemia, the risk of infection at the surgical site is higher than that in patients with $O A[19]$. In the current orthopedic department, enhanced recovery after surgery is strongly advocated, of which blood management is an essential component. In this randomized controlled trial, the pharmacokinetic characteristics of TXA were used to evaluate the efficacy and safety of multi-dose IV-TXA administration to RA patients, and to evaluate its optimal doses during the TKA perioperative period.

\section{Methods}

\section{Study design}

This was a single-center, single blind randomized controlled trial. This study was conducted at the Department of Orthopedics in Shanghai Guanghua Hospital of Integrated Traditional Chinese and Western Medicine and registered in the Chinese Clinical Trial Registry (ChiCTR1900025013). The Institutional Review Board (Ethics Committee of Shanghai Guanghua Hospital of Integrated Traditional Chinese and Western Medicine) give permission for our study. According to the Standards of Reporting Trials (CONSORT) recommendations for randomized controlled trials[20], and all participants gave their written informed consent before recruitment.

\section{Sample size calculation}

The sample size was calculated on the basis of the difference in the amount of HBL dependent on TXA therapy. The overall standard deviation is $\sigma=250$, and the allowable error estimate is $\delta=200$. These

values were estimated using the statistical formula

$$
n_{1}=n_{2}=2 \times\left[\frac{\left(\mathrm{z}_{\alpha / 2}+\mathrm{z}_{\beta}\right) / \sigma}{\delta}\right]^{2} .
$$

Predicting an estimated dropout rate of $10 \%, 104$ subjects will be required to yield a power of $90 \%$ with a significance level of 0.05 . 


\section{Patients}

From September 2019 to May 2020, we consecutively screened patients aged 50-75 years old who underwent primary unilateral TKA for RA. Doppler ultrasound examination without deep vein thrombosis (DVT). Exclusion criteria included a diagnosis other types of arthritis than RA. Renal dysfunction, or severe cardiovascular or cerebrovascular diseases, and patients with prolonged use of oral anticoagulant drugs. Elimination criteria included acquired color vision disorder; active intravascular coagulation patients; and a history of seizures.

\section{Randomized and drug delivery}

All eligible patients were randomized into two groups using computer-generated randomization, which was prepared by the statistician who was not involved in the trial and the group data was saved by the statistician. Allocation was concealed in consecutively numbered, sealed, opaque envelopes. IV-TXA ( $1 \mathrm{~g})$ was administered 10 min prior to skin incision by an anesthesiologist, and articular-injection TXA (1.5 g) was administered by the surgeon after cavity suture during the surgery. The patients were allocated into two groups, group A: one dose of IV-TXA ( $1 \mathrm{~g})$ at $3 \mathrm{~h}$ post-operatively; group B: three doses of IV-TXA (1 g) at 3,6 , and $12 \mathrm{~h}$ post-operatively. Dose administration was performed by a nurse after surgery. The surgeon, anesthesiologist, and statistician were blinded to the trial. Only the nurses knew of the patient s' enrolment.

\section{Perioperative anti-rheumatic treatment}

Methotrexate and hydroxychloroquine will be used during the perioperative period. Leflunomide will be discontinued one week before surgery. Use of other disease-modifying antirheumatic drugs will be discontinued two days before surgery, and restarted 1-2 days after gastrointestinal function recovery. The use of newer biologic agents such as tumor necrosis factor alpha will be discontinued 4 to 5 halflives before surgery and restarted after wound healing and infection elimination[21,22].

\section{Surgical procedure and postoperative management}

For perioperative prophylaxis, cefazolin sodium antibiotics were administered 30 min before surgery, and 24-48 $\mathrm{h}$ after surgery. General anesthesia was performed by anesthetists. The blood pressure was controlled to within $80-100 \mathrm{mmHg} / 60-70 \mathrm{mmHg}$ throughout the procedure. The tourniquet was inflated to $100 \mathrm{mmHg}$ above the systolic pressure before the incision and deflated after the closure of the incision. The surgery was performed by a single surgeon using the same technique. All patients received a surgeon-selected, cemented, posterior-stabilized prosthetic design with patellar resurfacing. These patients were not use drains and blood salvage after surgery. Postoperatively, the elastic bandage was compressed and bandaged on the surgery limb for $24 \mathrm{~h}$. The patients were discharged on the post- 
operative day (POD) 14 when they met discharge criteria, which included no wound leakage, swelling, and pain, or infection, independent mobility.

During hospitalization, all patients received physical prophylaxis and chemoprophylaxis for venous thromboembolism. Patients were asked to performed equal length contractions of the femoral quadriceps and ankle pump movements, lower-extremity strength training, and range of motion exercises on the day after surgery. At $6 \mathrm{~h}$ after surgery, perioperative oral rivaroxaban $(10 \mathrm{mg}$, once a day for 14 days) was prescribed to prevent thrombosis[23]. Blood transfusions were given when the post-operative $\mathrm{Hb}$ level less than $70 \mathrm{~g} / \mathrm{L}$ or any organ dysfunction related to anemia regardless of $\mathrm{Hb}$ level.[24]

\section{Outcome measurements}

Perioperative hematocrit (Hct), $\mathrm{Hb}$, coagulation index, and renal function were measured preoperatively, and on POD 1, 3, 7, and 14 .

Nadler's formula[25] was used to estimate patient blood volume (PBV) and the Gross[26] formula was used to calculate blood loss based on PBV and Hct drop.

Intraoperative blood loss (IBL) was estimated based on the amount of liquid in the negative pressure drainage bottle + amount of liquid in the gauze - amount of saline. A piece of gauze was soaked with approximately $20 \mathrm{~mL}$ of liquid.

$\mathrm{PBV}=\mathrm{K} 1 \times$ height $^{3}\left(\mathrm{~m}^{3}\right)+\mathrm{K} 2 \times$ weight $(\mathrm{kg})+\mathrm{K} 3$. Male: $\mathrm{K} 1=0.3669, \mathrm{~K} 2=0.03219, \mathrm{~K} 3=0.6041$. Female: $\mathrm{K} 1$ $=0.3561, \mathrm{~K} 2=0.03308, \mathrm{~K} 3=0.1833$. Total red blood cell loss $(\mathrm{TBL})=\mathrm{PBV} \times\left(\mathrm{Hct}_{\text {pre }}-\mathrm{Hct}_{\text {post }}\right) / \mathrm{Hct}_{\text {ave }}$ where $\mathrm{Hct}_{\text {pre }}=$ initial pre-operative Hct level, $\mathrm{Hct}_{\text {post }}=$ lowest Hct postoperative, $\mathrm{Hct}_{\text {ave }}=$ average of $\mathrm{Hct}_{\text {pre }}$ and $\mathrm{Hct}_{\text {post }}$. HBL is defined as TBL minus IBL plus transfusion. Thus, $\mathrm{HBL}=\mathrm{TBL}-\mathrm{IBL}+$ transfusion.

Patients were monitored for adverse events (DVT, Wound complications, Infection, Acute renal failure). Transfusion rate and adverse events were assessed post-operatively during inpatient hospital stay.

\section{Statistical analysis}

Analyses were performed using SPSS Version 25.0 (IBM Corp., Armonk, New York). Continuous-variable data were evaluated for a normal distribution with the Shaprio-Wilk test. They were presented as the means \pm standard deviations (SDs), and the difference between groups was compared using two independent sample t tests; Pearson's chi-square test was used for categorical variables. A $P$-value of less than 0.05 was considered statistically significant.

\section{Results}

\section{Patient characteristics}


Between September 2019 to May 2020, a total of 104 participants were assessed for eligibility. They were randomized to receive study medication and distributed homogeneously between two groups (52 in groups A and 52 in groups B). The duration of follow-up was two weeks, and 7 patients were lost during the follow-up period, for the following reasons: 3 discharge within 10 days, one had infection, and three refused to received blood products (Fig. 1). Patient demographic characteristics and per-operative variables were comparable between the two groups (Table 1).

Table 1

Preoperative and intraoperative characteristics of the patients

\begin{tabular}{|c|c|c|c|}
\hline $\begin{array}{l}\text { Variable } \\
\text { Mean } \pm \text { SD }\end{array}$ & $\begin{array}{l}\text { Group A } \\
(n=48)\end{array}$ & $\begin{array}{l}\text { Group B } \\
(n=49)\end{array}$ & $P$-value \\
\hline \multicolumn{4}{|l|}{ Patient characteristics } \\
\hline Age (y) & $66.4 \pm 5.9$ & $66.5 \pm 5.5$ & $0.921^{*}$ \\
\hline Gender (male/female), & $4 / 44$ & $6 / 43$ & $0.529 \triangle$ \\
\hline Body mass index $\left(\mathrm{kg} \mathrm{m}^{-2}\right)$ & $21.8 \pm 3.4$ & $22.4 \pm 3.1$ & $0.397^{*}$ \\
\hline Patient blood volume $(\mathrm{mL})$ & $3487.7 \pm 512.9$ & $3525.3 \pm 520.5$ & $0.721^{*}$ \\
\hline \multicolumn{4}{|l|}{ Preoperative laboratory values } \\
\hline Hematocrit (\%) & $36.1 \pm 3.2$ & $36.9 \pm 3.7$ & $0.215^{\star}$ \\
\hline Hemoglobin $(\mathrm{g} / \mathrm{L})$ & $117.5 \pm 13.9$ & $119.2 \pm 14.8$ & $0.565^{*}$ \\
\hline Platelets $\left(\times 10^{9} / \mathrm{L}\right)$ & $232.6 \pm 60.6$ & $226.3 \pm 60.2$ & $0.605^{*}$ \\
\hline D-dimer (mg/L) & $1.1 \pm 0.6$ & $1.0 \pm 0.5$ & $0.623^{*}$ \\
\hline Activated partial thromboplastin time (secs) & $26.3 \pm 4.0$ & $25.9 \pm 3.6$ & $0.685^{*}$ \\
\hline Fibrinogen (g/L) & $3.6 \pm 0.9$ & $3.7 \pm 1.1$ & $0.608^{*}$ \\
\hline Prothrombin time (secs) & $11.5 \pm 0.8$ & $11.3 \pm 0.6$ & $0.191^{*}$ \\
\hline International normalized ratio & $1.0 \pm 0.1$ & $1.0 \pm 0.1$ & $0.294^{*}$ \\
\hline Erythrocyte sedimentation rate $(\mathrm{mm} / \mathrm{h})$ & $38.0 \pm 18.8$ & $37.1 \pm 19.8$ & $0.819^{*}$ \\
\hline C-reactive protein (mg/L) & $11.2 \pm 7.3$ & $11.4 \pm 6.4$ & $0.902^{*}$ \\
\hline Intraoperative blood loss (mL) & $34.8 \pm 6.8$ & $34.5 \pm 7.1$ & $0.842^{*}$ \\
\hline
\end{tabular}




\section{Blood loss, maximum $\mathrm{Hb}$ drop, and transfusion rate}

Mean TBL, HBL, the drop in Hct and $\mathrm{Hb}$ were lower in group $B$ than group $A$. The level of D-dimer was lower in group $B$ than group $A$ on POD 1. No patient received a blood transfusion during the follow-up time (Table 2). 
Table 2

Primary and secondary outcomes regarding laboratory values after surgery

\begin{tabular}{|c|c|c|c|}
\hline $\begin{array}{l}\text { Variable } \\
\text { Mean } \pm \text { SD }\end{array}$ & $\begin{array}{l}\text { Group A } \\
(n=48)\end{array}$ & $\begin{array}{l}\text { Group B } \\
(n=49)\end{array}$ & $P$-value* \\
\hline \multicolumn{4}{|l|}{ Primary outcomes } \\
\hline Total red blood loss (mL) & $608.5 \pm 239.9$ & $506.1 \pm 227.0$ & 0.038 \\
\hline Hidden red blood loss (mL) & $571.0 \pm 237.3$ & $471.6 \pm 224.0$ & 0.036 \\
\hline Maximum hemoglobin drop & $23.7 \pm 9.4$ & $17.5 \pm 7.7$ & $<0.001$ \\
\hline \multicolumn{4}{|l|}{ Secondary outcomes } \\
\hline Transfusion (\%) & 0 & 0 & - \\
\hline \multicolumn{4}{|l|}{ Postop. Laboratory values } \\
\hline \multicolumn{4}{|l|}{ Hematocrit (\%) } \\
\hline POD 1 & $32.8 \pm 2.8$ & $34.1 \pm 3.5$ & 0.040 \\
\hline POD 3 & $30.4 \pm 2.6$ & $32.5 \pm 3.4$ & 0.001 \\
\hline POD 7 & $31.8 \pm 3.1$ & $33.5 \pm 3.5$ & 0.014 \\
\hline POD 14 & $33.8 \pm 2.8$ & $34.4 \pm 3.0$ & 0.346 \\
\hline \multicolumn{4}{|l|}{ Hemoglobin $(\mathrm{g} / \mathrm{L})$} \\
\hline POD 1 & $105.0 \pm 9.3$ & $108.7 \pm 12.4$ & 0.108 \\
\hline POD 3 & $94.2 \pm 9.3$ & $102.2 \pm 11.8$ & $<0.001$ \\
\hline POD 7 & $101.5 \pm 10.6$ & $106.8 \pm 12.3$ & 0.024 \\
\hline POD 14 & $109.2 \pm 8.8$ & $110.4 \pm 10.2$ & 0.542 \\
\hline \multicolumn{4}{|l|}{ D-Dimer (mg/L) } \\
\hline POD 1 & $5.5 \pm 2.9$ & $1.0 \pm 0.5$ & $<0.001$ \\
\hline POD 3 & $3.8 \pm 1.8$ & $3.8 \pm 2.1$ & 0.998 \\
\hline POD 7 & $3.6 \pm 1.4$ & $3.1 \pm 1.4$ & 0.085 \\
\hline POD 14 & $2.9 \pm 1.2$ & $2.7 \pm 1.2$ & 0.326 \\
\hline
\end{tabular}

\section{Complications and adverse events}


All incisions were healed by first intention, and no patient developed DVT, pulmonary embolism (PE), acute renal failure, or other adverse events. There were no statistically significant differences in calf vein thrombosis and superficial infection between two groups $(P>0.05$; Table 3$)$.

Table 3

Complications

\begin{tabular}{|llll|}
\hline Variable & $\begin{array}{l}\text { Group A } \\
(\mathbf{n = 4 8 )}\end{array}$ & $\begin{array}{l}\text { Group B } \\
(\mathbf{n = 4 9 )}\end{array}$ & P-value \\
\hline Deep vein thrombosis & 0 & 0 & \\
\hline Pulmonary embolism & 0 & 0 & \\
\hline Calf muscular vein thrombosis & 3 & 4 & $0.717^{\triangle}$ \\
\hline Superficial infection & 1 & 0 & $0.312^{\triangle}$ \\
\hline Deep prosthetic infection & 0 & 0 & \\
\hline Shock & 0 & 0 & \\
\hline Cardiac infarction & 0 & 0 & \\
\hline Wound complications & 0 & 0 & \\
\hline Acute renal failure & 0 & 0 & \\
\hline$\triangle$, Pearson's chi-square test. & & & \\
\hline
\end{tabular}

\section{Discussion}

Enhanced recovery after surgery (ERAS) is strongly advocated, and the management of perioperative blood loss is an essential component. The damage of peripheral blood vessels caused by stress caused by operation and the use of tourniquet during operation promote the occurrence of postoperative fibrinolysis and increase the amount of $\mathrm{HBL}$, which is the blood lost into the tissue intraoperatively and postoperatively accounting for approximately $50 \%$ of the TBL[27]. With the deflation of the tourniquet, the fibrinolysis around the wound reaches a peak within $6 \mathrm{~h}$ and maintained for $18 \mathrm{~h}[28]$. The half-life of TXA in plasma is $2-3 \mathrm{~h}[13]$, and the antifibrinolytic effect is maintained for approximately $8 \mathrm{~h}[29]$, after intravenous administration the $24 \mathrm{~h}$ recovery from urine is about $90 \%$ [13]. Based on in vivo and in vitro data, the effective therapeutic plasma concentration of tranexamic acid for inhibiting fibrinolysis to be 5$10 \mathrm{mg} / \mathrm{L}$ or $10-15 \mathrm{mg} / \mathrm{L}[29,30]$. According to the pharmacological characteristics of TXA, we believe that a single dose of IV-TXA $(1 \mathrm{~g})$ after surgery may not achieve the maximum antifibrinolytic effect.

The safety of multiple doses of TXA in OA patients undergo TKA has been confirmed by some studies. $[15,31,32]$ To our acknowledge, this study was the first study to observe the clinical effect of multi-dose TXA after TKA in patients with RA. We used 3 doses of IV-TXA $(1 \mathrm{~g})$ after surgery, the antifibrinolytic 
effect was maintained in the whole process of fibrinolysis, the HBL, the drop in $\mathrm{Hct}$ and $\mathrm{Hb}$ during hospitalization was lower than that of single dose. The levels of $\mathrm{Hct}$ and $\mathrm{Hb}$ in both groups decreased to the lowest level on POD 3, indicating that there was still persistent HBL within 3 days after surgery. Postoperative multiple doses of TXA can effectively maintain its blood concentration and reduce HBL.

Different from OA patients, the high expression of inflammatory factors such as IL-1, IL-6 and TNF- $a$ in RA patients leads to up-regulation of procoagulant factors and down-regulation of anticoagulation factors[33], we worry that post-operative repeat used IV-TXA may increase the incidence of DVT and PE. We evaluated the occurrence of DVT and PE by combining the clinical symptoms of patients, the level of D-dimer, Doppler ultrasound and pulmonary computed tomography. D-dimer responds to changes in blood coagulation and fibrinolysis in the body. An increase in the level of D-dimer is one of the signs of hypercoagulability and hyperfibrinolysis in the body, and it is the preferred index to evaluate whether DVT occurs[34]. D-dimer levels can increase under trauma, inflammation, and surgery[35]. Currently, $500 \mathrm{mg} /$ $L \mathrm{D}$-dimer is the cut-off value for the diagnosis of thrombosis. If the cut-off value is lower than that, thrombosis will be excluded[36]. The average level of D-dimer in group A was significantly higher than that in group $B$ within one day after surgery showing that three doses of IV-TXA postoperative could minimize fibrinolysis, and more effective inhibition of fibrinolysis contribute to less HBL after surgery.

There is a multi-strategic of blood management in perioperative period, including preoperative anemia assessment, minimally invasive surgery, shortening operation time, no use of tourniquet, use of antifibrinolytic drugs and postoperative nutritional supplement. Tourniquet can reduce intraoperative bleeding and facilitate bone-prosthesis adhesion, but increase the amount of HBL after operation[37]. Some studies have also shown that tourniquet increases the degree of pain in a short time after surgery, but does not increase the recovery time of knee function after TKA[38]. Under the principle of ERAS, it has been controversial whether to use tourniquet during operative. According to the Chinese expert guidelines for the prevention of venous thrombosis after TKA, anticoagulants should be used for at least 10-14 days, and postoperative lower limb functional rehabilitation training should be given to prevent the occurrence of venous thrombosis[39]. We use tourniquet during operation and give multi-dose TXA antifibrinolytic therapy after operation. Our perioperative blood management program can achieve a balance between bleeding and hemostasis, anticoagulation and anti-fibrinolysis.

There were some limitations in our stud. Firstly, the higher number of female patients than that of male patients which caused uneven male to female ratio. Secondly, owing post-operative blood loss and ethical considerations, we did not establish a placebo group to evaluate the effectiveness of TXA. Thirdly, the time of postoperative outcomes examination was not strictly 24 and 72 hours after operation, and we plan to design another study to obtain better and more accurate result. Fourthly, the functional recovery of knee after surgery was not evaluated in this study. Finally, although the half-life of TXA is short, the short follow-up time, may not be enough to fully assess the risk of DVT and other complications after multiple doses of IV-TXA in patients with RA, extending the follow-up time will be considered in future research. 


\section{Conclusion}

This prospective, randomized controlled trial based on multi-strategic of blood management strategies demonstrated that multiple-doses of IV-TXA can effectively reduce blood loss, a drop in Hct and $\mathrm{Hb}$ in patients with RA after TKA, and without increasing the risk of complications.

\section{Abbreviations}

IV-TXA: Intravenous tranexamic acid; RA: rheumatoid arthritis; TKA: Total knee arthroplasty; TXA: Tranexamic acid; TBL: Total red blood cell loss; HBL: Hidden red blood loss; Hb: hemoglobin; Hct: Hematocrit; DVT: Deep vein thrombosis; PE: pulmonary embolism; POD: Post-operative day; ERAS: Enhanced recovery after surgery.

\section{Declarations}

\section{Ethics approval and consent to participate}

This study had been approved by the ethics committee Shanghai Guanghua Hospital of Integrated Traditional Chinese and Western Medicine. Written informed consent to participate was obtained from all of the individual participants included in the study.

\section{Patient consent for publication}

Not required.

\section{Availability of data and materials}

The datasets used and analyzed during the current study are available from the corresponding author on reasonable request.

\section{Competing interests}

None declared.

\section{Funding}

This study was supported by the Foundation of Health and Family planning Commission of Shanghai (Grant No. ZY (2018-2020)-FWTX-6023). 


\section{Authors' contributions}

BXK and LBX conceived the study; BXK drafted the study; HX, CXG, JZ, JX, STS, YHM, and WTZ recruited the participants. XRX collected clinical data. CZ was responsible for statistical analyses and tables. BXK and LBX have primary responsibility for the final content. All authors contributed to writing and revising the paper and agreed to submission.

\section{Acknowledgement}

This study adheres to CONSORT guidelines. We are grateful to the participants who volunteered to participate in this research.

\section{Conferences}

1. Britsemmer K, Ursum J, Gerritsen M, Van Tuyl L, Van Schaardenburg D. Validation of the 2010 ACR/EULAR classification criteria for rheumatoid arthritis: Slight improvement over the 1987 ACR criteria. Ann Rheum Dis. 2011;70:1468-70.

2. Allen A, Carville S, McKenna F. Diagnosis and management of rheumatoid arthritis in adults: Summary of updated NICE guidance. BMJ. 2018;362:1-4.

3. Louie $\mathrm{GH}$, Ward MM. Changes in the rates of joint surgery among patients with rheumatoid arthritis in California, 1983-2007. Ann Rheum Dis. 2010;69:868-71.

4. Kumagai K, Harigane K, Kusayama Y, Tezuka T, Inaba Y, Saito T. Total knee arthroplasty improves both knee function and disease activity in patients with rheumatoid arthritis. Mod Rheumatol. 2017;27:806-10.

5. Tanaka N, Sakahashi H, Sato E, Hirose K, Ishima T, Ishii S. Timing of the administration of tranexamic acid for maximum reduction in blood loss in arthroplasty of the knee. J Bone Jt Surg. 2001;83:702-5.

6. Goyal L, Shah PJ, Yadav RN, Saigal R, Agarwal A, Banerjee S. Anaemia in newly diagnosed patients of rheumatoid arthritis and its correlation with disease activity. J Assoc Physicians India. 2018;66:26-9.

7. Ogbemudia AE, Yee SY, MacPherson GJ, Manson LM, Breusch SJ. Preoperative predictors for allogenic blood transfusion in hip and knee arthroplasty for rheumatoid arthritis. Arch Orthop Trauma Surg. 2013;133:1315-20.

8. Freedman J, Luke K, Escobar M,Vernich L,Chiavetta JA. Experience of a network of transfusion coordinators for blood conservation (Ontario Transfusion Coordinators [ONTraC]). Transfusion. 2008;48:237-50.

9. Henry DA, Carless PA, Moxey AJ, O'Connell D, Stokes BJ, Fergusson DA, Ker K. Anti-fibrinolytic use for minimising perioperative allogeneic blood transfusion. Cochrane Database Syst Rev.

2011;2011(3):CD001886. doi: 10.1002/14651858.CD001886.pub4 
10. Themistoklis T, Theodosia V, Konstantinos K, Georgios DI. Perioperative blood management strategies for patients undergoing total knee replacement: Where do we stand now? World J Orthop. 2017;8:441-54.

11. Bedard NA, Pugely AJ, Lux NR, Liu SS, Gao Y, Callaghan JJ. Recent Trends in Blood Utilization After Primary Hip and Knee Arthroplasty. J Arthroplasty. 2017;32:724-7.

12. Aglietti P, Baldini A, Vena LM, Abbate R, Fedi S, Falciani M. Effect of tourniquet use on activation of coagulation in total knee replacement. Clin Orthop Relat Res. 2000;169-77.

13. Åstedt B. Clinical pharmacology of tranexamic acid. Scand J Gastroenterol. 1987;22:22-5.

14. Cid J, Lozano M. Tranexamic acid reduces allogeneic red cell transfusions in patients undergoing total knee arthroplasty: Results of a meta-analysis of randomized controlled trials. Transfusion. 2005;45:1302-7.

15. Tzatzairis T, Drosos GI, Vogiatzaki T, Tilkeridis K, Ververidis A, Kazakos K. Multiple intravenous tranexamic acid doses in total knee arthroplasty without tourniquet: a randomized controlled study. Arch Orthop Trauma Surg. 2019;139:859-68.

16. Xie J, Ma J, Yao H, Yue C, Pei F. Multiple Boluses of Intravenous Tranexamic Acid to Reduce Hidden Blood Loss After Primary Total Knee Arthroplasty Without Tourniquet: A Randomized Clinical Trial. J Arthroplasty. 2016;31:2458-64.

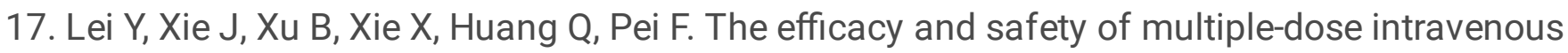
tranexamic acid on blood loss following total knee arthroplasty: a randomized controlled trial. Int Orthop. 2017;41:2053-9.

18. Jennings JD, Solarz MK, Haydel C. Application of Tranexamic Acid in Trauma and Orthopedic Surgery. Orthop Clin North Am. 2016;47:137-43.

19. Ljungqvist O. ERAS - Enhanced Recovery after Surgery: Moving Evidence-Based Perioperative Care to Practice. J Parenter Enter Nutr. 2014;38:559-66.

20. Moher D, Schulz KF, Altman D. The CONSORT Statement: revised recommendations for improving the quality of reports of parallel-group randomized trials 2001. Explore (NY). 2005;1:40-5.

21. Krause ML, Matteson EL. Perioperative management of the patient with rheumatoid arthritis. World J Orthop. 2014;5:283-91.

22. Thorsness RJ, Hammert WC. Perioperative management of rheumatoid medications. J Hand Surg Am. 2012;37:1928-31.

23. National Institute for Health. Rivaroxaban for the prevention of venous thromboembolism after total hip or total knee replacement in adults. 2010.

24. Wang D, Wang HY, Luo ZY,Meng WK, Pei FX,Li Q, Zhou ZK, Zeng WN. Blood-conserving efficacy of multiple doses of oral tranexamic acid associated with an enhanced-recovery programme in primary total knee arthroplasty: a randomized controlled trial. Bone Joint J. 2018;100-B(8):1025-1032.

25. Nadler SB, Hidalgo JH, Bloch T. Prediction of blood volume in normal human adults. Surgery. 1962;51:224-32. http://www.ncbi.nlm.nih.gov/pubmed/21936146. 
26. Gross JB. Estimating allowable blood loss: Corrected for dilution. Anesthesiology. 1983;58:277-80. doi:10.1097/00000542-198303000-00016.

27. Sehat KR, Evans R, Newman JH. How much blood is really lost in total knee arthroplasty? Correct blood loss management should take hidden loss into account. Knee. 2000;7:151-5.

28. Blanié A, Bellamy L, Rhayem Y, Flaujac C, Samama CM, Fontenay M, Rosencher N. Duration of postoperative fibrinolysis after total hip or knee replacement: A laboratory follow-up study. Thromb Res. 2013;131:e6-11.

29. Benoni G, Björkman S, Fredin H. Application of Pharmacokinetic Data from Healthy Volunteers for the Prediction of Plasma Concentrations of Tranexamic Acid in Surgical Patients. Clin Drug Investig. 1995;10:280-7.

30. Fiechtner BK, Nuttall GA, Johnson ME, Dong Y, Sujirattanawimol N, Oliver Jr WC,Sarpal RS, Oyen LJ, Ereth MH. Plasma tranexamic acid concentrations during cardiopulmonary bypass. Anesth Analg. 2001;92:1131-6.

31. Tang Y, Wen Y, Li W, Li H, Yang Y, Liu Y. The efficacy and safety of multiple doses of oral tranexamic acid on blood loss, inflammatory and fibrinolysis response following total knee arthroplasty: A randomized controlled trial. Int J Surg. 2019;65:45-51.

32. Zhang S, Xie J, Cao G, Lei Y, Huang Q, Pei F. Six-Dose Intravenous Tranexamic Acid Regimen Further Inhibits Postoperative Fibrinolysis and Reduces Hidden Blood Loss Following Total Knee Arthroplasty. 2019;10.1055/s-0039-1694768.

33. Van Den Oever IAM, Sattar N, Nurmohamed MT. Thromboembolic and cardiovascular risk in rheumatoid arthritis: Role of the haemostatic system. Ann Rheum Dis. 2014;73:954-7.

34. Jovanović M, Milić D, Djindjić B, Jovanović J, Stanojević G, Stojanović M. Importance of D-dimer Testing in Ambulatory Detection of Atypical and "Silent" Phlebothrombosis. Vojnosanit Pregl. 2010;67(7):543-547.

35. Knowlson L, Bacchu S, Paneesha S, McManus A, Randall K, Rose P. Elevated D-dimers are also a marker of underlying malignancy and increased mortality in the absence of venous thromboembolism. J Clin Pathol. 2010;63(9):818-822.

36. Righini M, Perrier A, De Moerloose P, Bounameaux H. D-Dimer for venous thromboembolism diagnosis: 20 years later. J Thromb Haemost. 2008;6:1059-71.

37. Schnettler T, Papillon N, Rees H. Use of a Tourniquet in Total Knee Arthroplasty Causes a Paradoxical Increase in Total Blood Loss. J Bone Joint Surg Am. 2017;99(16):1331-1336.

38. Alexandersson M, Wang EY, Eriksson S. A small difference in recovery between total knee arthroplasty with and without tourniquet use the first 3 months after surgery: a randomized controlled study. Knee Surgery, Sport Traumatol Arthrosc. 2019;27:1035-42.

39. Yue C, Zhou Z, Pei F, Weng X, Qiu G,Ruan C. Chinese Hip and Total Knee Arthroplasty Surgery Perioperative Antifibrinolytic Drug Sequential Anticoagulant Application Programme Expert Consensus. Chinese J Bone Jt Surg. 2015;8:281-5. 


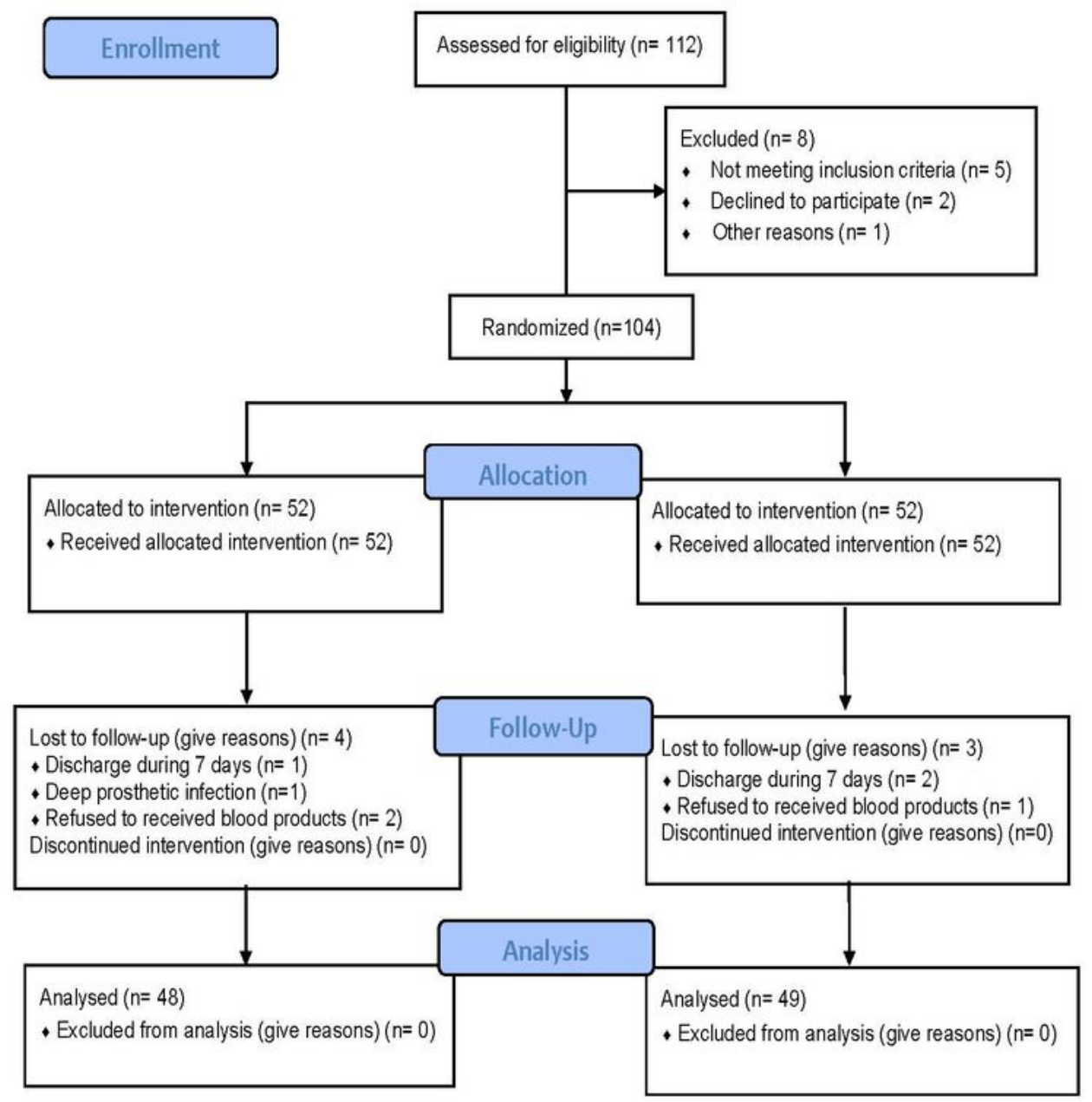

Figure 1

COMSORT (Consolidated Standards of Reporting) flow diagram.

\section{Supplementary Files}


This is a list of supplementary files associated with this preprint. Click to download.

- datasharing.docx

- Consort2010Checklist2.doc

- flowchart.doc 